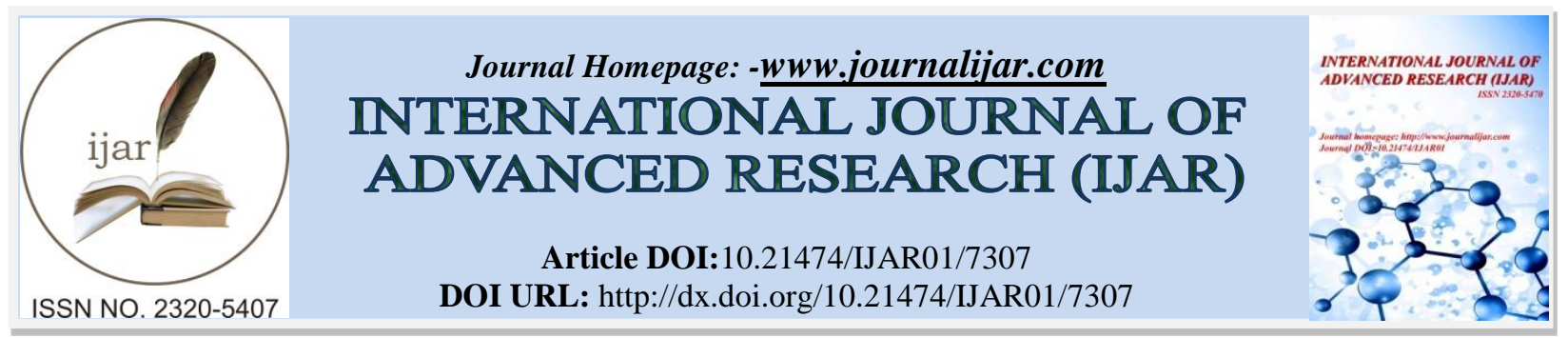

RESEARCH ARTICLE

\title{
ROLE OF CONTINUOUS AND COMPREHENSIVE EVALUATION (CCE) IN ATTAINING EDUCATIONAL OBJECTIVES AT UPPER PRIMARY LEVEL WITH REGARD RESPONDENTS HAVING CCE MANUAL AND MANAGEMENT OF SCHOOL.
}

S.Mabel soruba rani and dr. M. Suganthi.

1. Ph. D Scholar Alagappa University,College of Education, Karaikudi - 630003.

2. Assistant Professor, Alagappa University, College of Education, Karaikudi - 630003.

\section{Manuscript Info}

Manuscript History

Received: 17 April 2018

Final Accepted: 19 May 2018

Published: June 2018

Keywords:-

CCE, manual, management.

\begin{abstract}
Reforms bring life into school education system. One of them is examination reform suggested by various committees and commissions. In the present study, role of Continuous and Comprehensive Evaluation (CCE) in attaining educational objectives at upper primary level with respect to respondents having CCE manual and management of school were studied. To study the significance difference between and among the variables, ' $t$ ' and $F$ test were applied. The results indicate that there is significant difference in the Mean Score between the role of CCE in attaining educational objectives at upper primary level with respect to having CCE manual and there is significant difference among the mean scores of role of CCE in attaining educational objectives at upper primary level with respect to management of the school.
\end{abstract}

Copy Right, IJAR, 2018,. All rights reserved.

\section{Introduction:-}

Evaluation is one of the most important part of any active system. Evaluation is an important tool in the hands of the teachers to help the learners to improve their achievement in scholastic and non-scholastic areas. Continuous and Comprehensive Evaluation keeps the learner continuously on the track and involved.

\section{Review Of Related Literature:-}

T.S.Anitha (2014) conducted A Comparative study on the Opinion of Government and private school teachers of Chittoor district towards Continuous Comprehensive Evaluation.

The main objective of the study is to find out the opinion of teachers towards continuous and comprehensive evaluation. Accordingly the hypotheses were formulated. For this purpose the sample of 100 teachers were purposively selected. After establishing proper rapport the questionnaire was administered to the subjects. The data was scored according to the scoring procedure given in the manual. To study the significance of difference between the various groups ' $t$ ' test was applied. The overall results indicated that there is significant difference between the opinion of school teachers towards continuous and comprehensive evaluation in relation to Gender and type of management of school. 
John Silvester .S (2013) made a research work on, The effectiveness of CCE on the Achievement of Educational Objectives of Elementary School Education Recommended by NCF, 2005.

The investigator formulated the following objective to find out the level of effectiveness of CCE on the achievement of educational objectives recommended by NCF 2005 with regard to Gender, Locality, Types of School, Types of Management and Nature of School. The findings showed that there is no significant difference in the level of effectiveness of CCE on the achievement of educational objectives of elementary school education recommended by NCF 2005 with regard to Gender, Locality, Types of School and Types of Management. But there is significant difference in the level of effectiveness on the achievement of educational objectives of elementary school education recommended by NCF 2005.

\section{Need And Significance Of The Study:-}

After the introduction of CCE to schools, government took steps to train the teachers of all type of schools for effective implementation of CCE. Newly appointed teachers also got the training with CCE manual and general guidelines. CCE refresher training also conducted to strengthen the knowledge in CCE. The investigator felt to study the role of CCE in attaining educational objectives at upper primary level with regard to respondents having CCE manual and management of school.

\section{Objectives:-}

1. To find out there is any significant difference between the mean scores of role of CCE in attaining educational objectives at upper primary level with respect to having CCE manual.

2. To find out there is any significant difference among the mean scores of role of CCE in attaining educational objectives at upper primary level with respect to management of the school.

\section{Hypotheses:-}

1. There is no significant difference between the mean scores of role of CCE in attaining educational objectives at upper primary level with respect to having CCE manual.

2. There is no significant difference among the mean scores of role of CCE in attaining educational objectives at upper primary level with respect to management of the school.

\section{Methodology:-}

Survey method was adopted in present study.

Population:-

Teachers handling 6,7 and $8^{\text {th }}$ standard in Middle schools in Tiruppur district.

Sample:-

351 teachers working in Tiruppur district middle schools.

Tool And Technique:-

To collect the data researcher made CCE scale was used. To find out the result ' $t$ ' and F test were used.

\section{Data Analysis And Findings:-}

\section{Hypothesis 1:-}

There is no significant difference between the mean scores of role of CCE in attaining educational objectives at upper primary level with respect to having CCE manual.

Table 1:- t- Test for the Mean Difference between the role of CCE in attaining educational objectives at upper primary level with respect to having CCE manual.

\begin{tabular}{|c|c|c|c|c|c|}
\hline $\begin{array}{c}\text { Having CCE } \\
\text { Manual }\end{array}$ & N & Mean & $\begin{array}{c}\text { Standard } \\
\text { Deviation }\end{array}$ & $\begin{array}{c}\text { Calculated 't' } \\
\text { value }\end{array}$ & Remarks \\
\hline Yes & 334 & 236.36 & 29.079 & 2.813 & \multirow{2}{*}{$\mathrm{S}$} \\
\hline No & 17 & 216.12 & 25.964 & & \\
\hline
\end{tabular}


It is inferred from the above table (1) shows that, the calculated t-value (2.813) is greater than the table value (1.96) at $5 \%$ level of significance. Hence the null hypothesis, "There is no significant difference between the mean scores of role of CCE in attaining educational objectives at upper primary level with respect to having CCE manual" is rejected. It shows that there is significant difference in the Mean Score between the role of CCE in attaining educational objectives at upper primary level with respect to having CCE manual.

\section{Hypothesis 2:-}

There is no significant difference among the mean scores of role of CCE in attaining educational objectives at upper primary level with respect to management of the school.

Table 2:-Analysis of variance among the Mean Score of role of CCE in attaining educational objectives at upper primary level with respect to management of the school

\begin{tabular}{|l|c|c|c|c|c|}
\hline $\begin{array}{c}\text { Source of } \\
\text { Variance }\end{array}$ & Sum of Squares & Df & Mean & $\begin{array}{c}\text { Calculated 'F' } \\
\text { value }\end{array}$ & Remark \\
\hline Between Groups & 9052.697 & 2 & 4526.349 & 5.433 & \\
\cline { 1 - 1 } Within Groups & 289949.907 & 348 & 833.189 & & $\mathrm{~S}$ \\
\hline
\end{tabular}

It is inferred from the above table (2) shows that, the calculated F-value (5.433) is greater than the table value (2.99) at 5\% level of significance. Hence the null hypothesis, "There is no significant difference among the mean scores of role of CCE in attaining educational objectives at upper primary level with respect to management of the school" is rejected. It shows that there is significant difference among the mean scores of role of CCE in attaining educational objectives at upper primary level with respect to management of the school.

Table 3:- The Scheffe test showing the significant difference in role of CCE in attaining educational objectives at upper primary level

\begin{tabular}{|c|c|c|c|}
\hline \multicolumn{2}{|c|}{ Mean Difference in role of CCE in attaining educational objectives at upper primary level } & \multirow{2}{*}{ Result } \\
\hline Municipal & Panchayath & Others & - \\
\hline 239.31 & 232.57 & - & - \\
\hline 239.31 & - & 248.39 & $*$ \\
\hline- & 232.57 & 248.39 & $*$ \\
\hline
\end{tabular}

*Significant difference at $5 \%$ level of significance

The Scheffe result shows that there is significant difference between the respondents from Panchayath schools and respondents from other schools.It is inferred from the above table that the respondents from Panchayath schools have greater role of $\mathrm{CCE}$ in attaining educational objectives at upper primary level than the respondents from other schools.

\section{Discussion:-}

The CCE manual was distributed to the teachers. It helps them implement the student-friendly CCE effectively. The activities have been designed so meticulously that teachers would naturally find it easy to use, adopt or create their own activities to witness and assess the miracle of learning happening in the class room in a fear-free, friendly and enabling environment. It deals with scholastic, co-scholastic activities and curricular subjects. The formal assessment for learning and remedial activities are given for ensuring relearning and it has no scope for remedial measures. In this radical method of assessment, teachers assess not only the learning and achievement but also the students' social graces, their knowledge and application of social skills through activities. The study of Tewari (1975) revealed that teachers were not trained in evaluation techniques.

In the study, it was found that there was a significant difference in the role of CCE in attaining educational objectives at upper primary level with respect to Management of the school. There was significant difference between panchayat schools and others. However, in contradict to the present study by John Silvester (2013) showed that there is no significant difference in the level of effectiveness of CCE on the achievement of educational objectives of elementary school education recommended by NCF 2005 with regard to Management of the school. In addition to the present study by Anitha (2014) indicated that there is significant difference between the opinion of school teachers towards continuous comprehensive evaluation in relation to management of school. 


\section{Conclusion:-}

Training given to teachers with guidelines and manual is useful to them to implement CCE in their schools. One or two days training for teachers is not enough to implement, if they have the manual it helps them a lot. Municipal, Panchayath, and other schools teachers got the same training, but there is significant difference between panchayath and other schools. This may due to the facilities in schools, cooperation from students and parents etc.,

\section{References:-}

1. http://www.cbse.nic.in

2. http://cbse.nic.in/workeducation.pdf

3. Kothari, R. G., \& Thomas, V. M. (2012). A study of implementation of continuous and comprehensive evaluation in upper primary schools of Kerala. MIER Journal of Educational Studies, Trends \& Practices. 2 (2): 168-176.

4. Kumar, T.P. (2014). Teachers' attitude towards continuous and comprehensive evaluation. Golden Research Thoughts.3 (8): 1-5.

5. Mondal, A., \& Mete, J. (2013). Continuous and comprehensive evaluation - An appraisal. Issues and Ideas in Education. 1(2):121-138 